\title{
Degenerative changes in adolescent spines: a comparison of motocross racers and age-matched controls
}

\author{
David J. Daniels, MD, PhD, ${ }^{1}$ T. David Luo, MD, ${ }^{2}$ Ross Puffer, MD, ${ }^{1}$ Amy L. McIntosh, MD, ${ }^{2}$ \\ A. Noelle Larson, MD, ${ }^{2}$ Nicholas M. Wetjen, MD, ${ }^{1}$ and Michelle J. Clarke, MD${ }^{1}$ \\ Departments of ${ }^{1}$ Neurosurgery and ${ }^{2}$ Orthopedic Surgery, Mayo Clinic College of Medicine, Mayo Clinic, Rochester, Minnesota
}

OBJECT Motocross racing is a popular sport; however, its impact on the growing/developing pediatric spine is unknown. Using a retrospective cohort model, the authors compared the degree of advanced degenerative findings in young motocross racers with findings in age-matched controls.

METHODS Patients who had been treated for motocross-related injury at the authors' institution between 2000 and 2007 and had been under 18 years of age at the time of injury and had undergone plain radiographic or CT examination of any spinal region were eligible for inclusion. Imaging was reviewed in a blinded fashion by 3 physicians for degenerative findings, including endplate abnormalities, loss of vertebral body height, wedging, and malalignment. Acute pathological segments were excluded. Spine radiographs from age-matched controls were similarly reviewed and the findings were compared.

RESULTS The motocross cohort consisted of 29 riders (mean age 14.7 years; $82 \%$ male); the control cohort consisted of 45 adolescents (mean age 14.3 years; $71 \%$ male). In the cervical spine, the motocross cohort had 55 abnormalities in 203 segments (average 1.90 abnormalities/patient) compared with 20 abnormalities in 213 segments in the controls (average 0.65/patient) ( $p=0.006$, Student t-test). In the thoracic spine, the motocross riders had 51 abnormalities in 292 segments (average 2.04 abnormalities/patient) compared with 25 abnormalities in 299 segments in the controls (average 1.00 /patient) ( $p=0.045$ ). In the lumbar spine, the motocross cohort had 11 abnormalities in 123 segments (average 0.44 abnormalities/patient) compared with 15 abnormalities in 150 segments in the controls (average 0.50/patient) $(p=0.197)$.

CONCLUSIONS Increased degenerative changes in the cervical and thoracic spine were identified in adolescent motocross racers compared with age-matched controls. The long-term consequences of these changes are unknown; however, athletes and parents should be counseled accordingly about participation in motocross activities.

http://thejns.org/doi/abs/10.3171/2014.9.PEDS14153

KEY WORDS motocross; sports injuries; spine trauma; pediatric spine trauma; degenerative changes

$\mathrm{M}$ ОтосRоss has been a popular sport among children and adolescents since the 1960s. ${ }^{2}$ It is a nationally organized competition through the American Motorcyclist Association and involves riding 2-wheeled motorized bikes around enclosed outdoor tracks over rough terrain and various obstacles. Youth motocross riders compete in age-based groups beginning as young as age $4 .^{25}$ The increasing popularity has led to a rise in motocross-associated morbidity and injuries requiring surgical intervention. . $^{72,14,22,25,26}$ Trauma to the extremities is most common, accounting for $52 \%-72 \%$ of all motocross injuries. ${ }^{12,14,16}$ Injury to the spine is rare, comprising 5.8\% of all motocross-related fractures in the general population, although one-third of these led to permanent neurological damage. ${ }^{16}$
Although catastrophic sports injuries to the spine have received a great deal of attention, less is known about the long-term effects of the chronic repetitive stress of noncollision contact sports and motorsports. ${ }^{43}$ This is especially concerning for the active youth motocross rider, as there are no data on the impact of motocross racing on the growing and developing pediatric spine. In other repetitiveimpact sports, radiographic markers of premature degenerative spine disease have been noted..$^{10,11,21,23,30,31,34,35,37-39}$ However, the long-term sequelae of accelerated cervical spondylosis are unclear, although decreased range of motion, ${ }^{24}$ axial pain, ${ }^{1}$ radicular symptoms, and higher risk of spinal cord injury due to spinal stenosis, ${ }^{3,6,36}$ are theorized.

We noticed a concerning number of degenerative findings throughout the spines in many of the patients being 
treated for motocross injuries at our institution. The purpose of this study was to analyze the degree of degenerative change in the spine of pediatric motocross riders in comparison with age-matched controls. We hypothesized that there is an increase in the number of degenerative spine abnormalities in the motocross cohort.

\section{Methods}

This study was a retrospective age-matched case control study of patients under age 18 who were treated for motocross injuries at our institution between 2000 and 2007 and a control cohort of non-motocross riders. Approval was obtained from the Mayo Clinic Institutional Review Board for all aspects of the study. Only patients with high-quality plain radiographs or CT scans with sagittal and coronal reconstructions of any spinal region were included in the study.

Controls were selected from patients under the age of 18 who were not involved in motocross and had undergone $\mathrm{CT}$, MRI, or plain radiographic examination of the spine for any reason during the same time period. The group from whom the controls were selected included patients in our trauma database who had sustained injuries in motor vehicle collisions or had sport-related injuries such as those occurring in football and gymnastics as well as patients with brain tumors who underwent spinal imaging.

The imaging studies were reviewed for degenerative abnormalities by 2 physicians: 2 neurosurgeons and 1 radiologist. These reviewers were blinded to the patient's cohort and analyzed imaging studies independently. All discrepancies in individual patients were agreed upon by consensus before data analysis. Particular focus was given to endplate abnormalities (irregularity or discontinuity), disc abnormalities (loss of height, gas, schmoral's nodes) loss of vertebral body height $>10 \%$ compared with average of adjacent levels), vertebral body wedging ( $>10 \%$ difference in height between anterior and posterior cortex), and malalignment (kyphotic deformities, listhesis). Segments with acute pathologies, such as fractures, were excluded. Spine imaging studies from the age-matched controls were similarly evaluated. Statistical analysis was performed using the Student t-test, and $\mathrm{p}$ values were reported to show the probability of having a significant association with the significance level set at 0.05 .

\section{Results}

There were 298 motocross injuries in 248 motocross riders evaluated at our institution during the study period. Of these 248 patients, 29 had imaging studies qualifying them for this study. The mean age of the 29 patients in the motocross cohort was 14.7 years (range 10-17 years), and $24(83 \%)$ of these patients were male (Table 1). The control group consisted of 45 patients with a mean age of 14.3 years (range $11-17$ years), including 32 males (71\%).

\section{Cervical Spine}

We reviewed 203 cervical segments in 29 motocross riders. There were 55 abnormal segments (27.1\%) and no fractures, for a mean of 1.9 abnormalities per section
TABLE 1. Demographic and clinical characteristics

\begin{tabular}{lcc}
\hline \multicolumn{1}{c}{ Characteristic } & $\begin{array}{c}\text { Motocross } \\
\text { Cohort }\end{array}$ & Controls \\
\hline No. of patients & 29 & 45 \\
\hline Mean age \pm SD (yrs) & $14.7 \pm 2.0$ & $14.3 \pm 1.4$ \\
\hline No. of male patients (\%) & $24(83)$ & $32(71)$ \\
\hline Cervical spine & & \\
\hline No. of imaging studies reviewed & 29 & 31 \\
\hline No. of fractures & 0 & 4 \\
\hline Thoracic spine & & \\
\hline No. of imaging studies reviewed & 25 & 25 \\
\hline No. of fractures & 8 & 1 \\
\hline Lumbar spine & & \\
\hline No. of imaging studies reviewed & 25 & 30 \\
\hline No. of fractures & 2 & 0 \\
\hline
\end{tabular}

(Fig. 1A). In the control cohort, we reviewed 217 cervical segments in 31 patients. Four segments were excluded because of fractures. In the remaining 213 segments, there were 20 abnormalities $(9.4 \%)$ for a mean of 0.65 per patient. Thus there was a 2.9-fold increase in degenerative changes in the cervical spines of the motocross riders ( $\mathrm{p}=$ 0.006) (Table 2, Fig. 2).

\section{Thoracic Spine}

We reviewed 300 thoracic segments in 25 motocross riders. Eight segments were excluded for fractures. In the
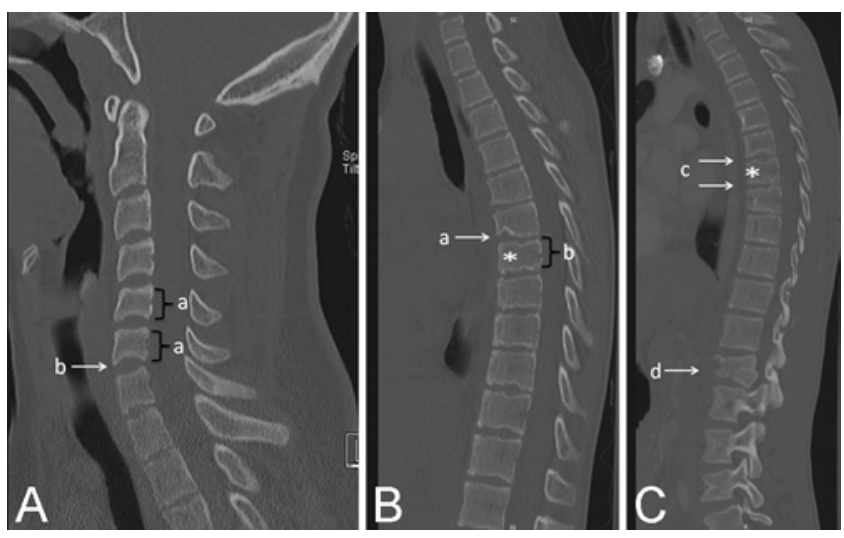

FIG. 1. Representative CT images. A: Example of a cervical spine in a 16 -year-old male motocross racer. There is approximately $20 \%$ loss of vertebral body height (a) at C-5 and C-6 compared with the immediate adjacent levels. There is also loss of normal lordosis and there is focal malalignment at $\mathrm{C} 6-7$ (b). In the analysis of degenerative findings, this adolescent was considered to have 3 abnormalities ( 2 segments with loss of height and 1 instance of abnormal alignment). B: This is an example of the thoracic spine in 12-year-old female motocross racer. There is an endplate abnormality (a), loss of vertebral body height (b), and kyphosis in the midthoracic region (asterisk). This girl was considered to have 3 abnormalities based on these degenerative findings. C: Example of a thoracic spine in a 17-year-old male motocross rider. Prominent Schmorl's nodules are seen at adjacent disc spaces (c) with kyphosis (asterisk). An acute pathological fracture (d) caused the affected vertebral segment to be excluded from the analysis. A total of 3 degenerative findings were observed. 
remaining 292 segments, there were 51 abnormalities $(17.5 \%)$ for a mean of 2.04 per patient (Fig. 1B). In the control cohort, we also reviewed 300 segments in 25 patients. One segment was excluded due to fracture. There were 25 abnormalities in the remaining 299 segments (8.4\%) for a mean of 1.00 per patient. Thus there was a 2.0 -fold increase in degenerative changes in the thoracic spines of the motocross riders $(p=0.045)$ (Table 2, Fig. 2$)$.

\section{Lumbar Spine}

We reviewed 125 lumbar segments in 25 motocross riders. Two segments were excluded for fractures. In the remaining 123 segments, there were 11 abnormalities (8.9\%) for a mean of 0.44 per patients. In the control cohort, we reviewed 150 segments in 30 patients. There were $15 \mathrm{ab}-$ normal segments $(10.0 \%)$ and no fractures, for a mean of 0.50 abnormalities per patient. No statistically no significant difference was observed between the two cohorts ( $\mathrm{p}$ $=0.197)($ Table 2 , Fig. 2).

\section{Discussion}

Participation in sports exposes athletes to theoretical risk factors for spinal degeneration not seen in the general population..$^{43}$ These risks include altered body mechanics, acute bony and soft-tissue injuries, high-force impacts, and repetitive loads. . $^{10,11,27,29,40,43,45}$ Further, in younger athletes who have not gained mastery of their sport and are in the process of both growing and gaining sport-specific strength and skills, these risks are likely increased. Most

TABLE 2. Degenerative abnormalities for the cervical, thoracic, and lumber spine*

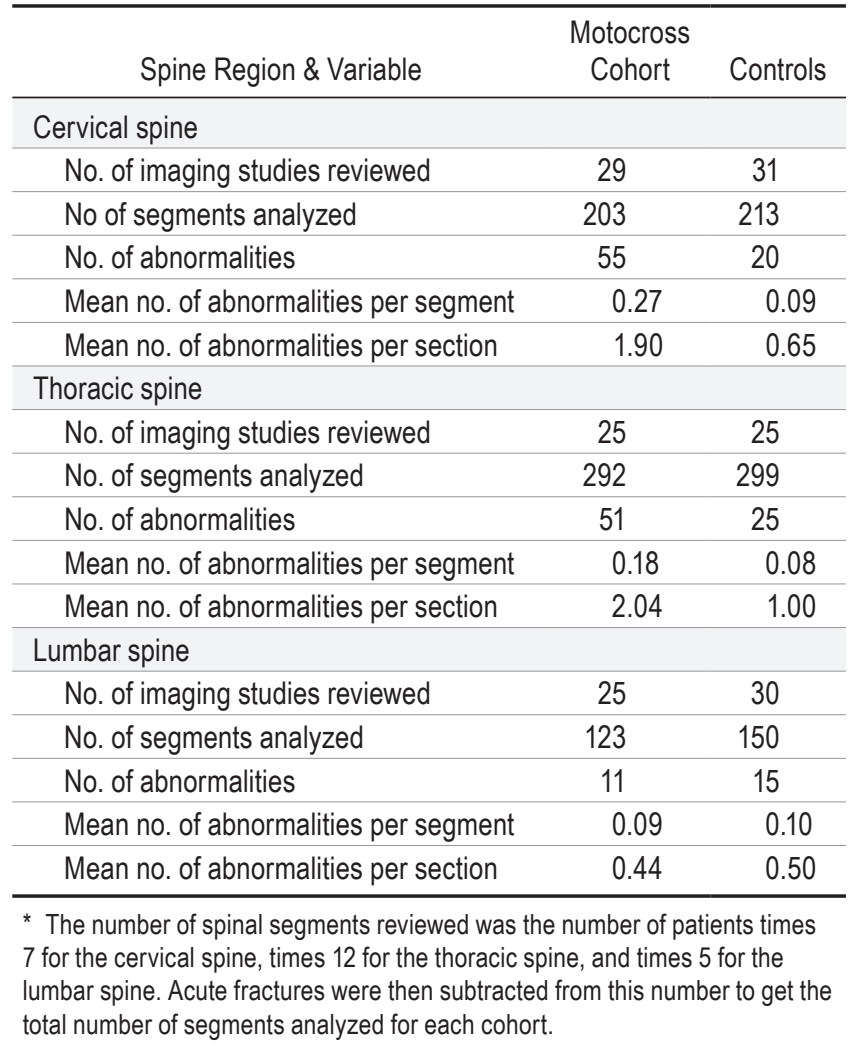

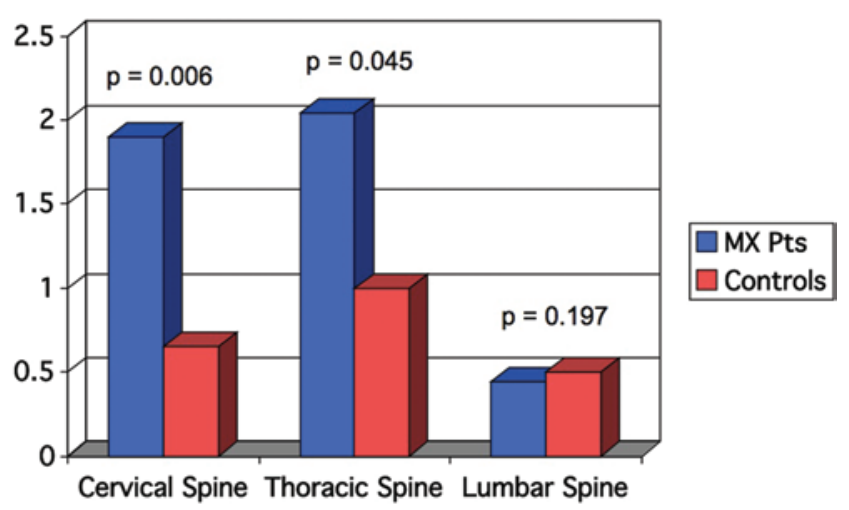

FIG. 2. Comparison of degenerative changes in the controls and the motocross (MX Pts) cohort. We found a 2.9-fold increase in cervical changes and a 2-fold increase in thoracic degenerative changes in the motocross riders compared with age-matched controls, while no difference was observed in the lumbar spine. The $y$-axis indicates the mean number of degenerative changes per patient. Figure is available in color online only.

studies have focused on acute, catastrophic injuries, although some studies have looked at the long-term consequences on spinal column degeneration due to repetitive impact contact and noncontact sports, but these data are fairly limited. ${ }^{10,11,21,23,30,31,34,35,37-39}$

In the present study, we observed more degenerative findings in the cervical and thoracic spines of motocross racers than in the corresponding spine regions of agematched controls. The reason for this is unclear, but it may be due to the repetitive microtrauma from the jarring of the motocross bike on the dirt track, or it could be a cumulative effect of multiple high-velocity motocross accidents sustained in practice and competition. This mirrors the increase in degenerative changes noted in athletes participating in other contact and non-contact impact sports such as rugby, ${ }^{11,30,35,36}$ football, ${ }^{1,3,10,11,39}$ soccer, ${ }^{21}$ gymnastics, ${ }^{23}$ equestrian activities,,${ }^{19,44}$ and diving. ${ }^{38}$ In fact, our control cohort contained a high-performance adolescent gymnast and a child injured on an all-terrain vehicle; when these 2 patients were removed from the control cohort, the results demonstrated an even greater significant difference in thoracic degeneration between controls and the motocross riders (2.9-fold increase instead of 2.0-fold, $\mathrm{p}=0.012$ instead of $\mathrm{p}=0.045$ ).

Additionally, the repetitive nature of the stresses may be important, as even sports considered to entail relatively low impact and no collision risk are associated with an increased number of degenerative spine changes than the general population. ${ }^{37}$ However, although these changes are consistent throughout the literature, they have not been noted universally, and it is notable that, as athletes have greater fitness, muscle bulk, and overall strength than the general population, their training may have a protective and stabilizing effect. Additionally, most studies involve high-performance athletes, and the changes that are observed in these athletes may not be as pronounced in hobby enthusiasts. For instance, in a group of asymptomatic lifelong athletes over 40 years of age, no increase in degenerative findings was seen in comparison with findings from other population-based studies. ${ }^{17}$ The present study 
is limited by small patient numbers and may be skewed based on known age-related changes.

Interestingly, we did not find a difference in the number of degenerative changes in the lumbar spine between the motocross and non-motocross cohorts. In many studies, degenerative lumbar changes have been noted in athletes in whom sport-related loading is transferred along the spinal axis..$^{10,11,29,40,45}$ It is unclear why the cervical and thoracic spine is at higher risk for degenerative changes than the lumbar spine in motocross participants. This may be due to riding posture and common impact modalities, although the variety of head, trunk, and extremity injuries ${ }^{22,25}$ reported for the pediatric motocross population speaks to the violence and variety of accidents that occur; there would be no obvious reason to exclude the lumbar spine.

The long-term implications of increased degenerative changes in pediatric athletes are unknown. Long-term participation in football has been implicated in the development of premature osteoarthritis..$^{13,43,46}$ One study notes that $36.6 \%$ of retired NFL players aged $30-49$ years reported neck pain lasting most of the day compared with only $9.4 \%$ of a general population cohort of the same age. ${ }^{46}$ In a cohort of retired elite gymnasts in whom multiple degenerative changes, including spondylolysis and spondylolisthesis, were seen, 15 of 24 complained of back pain during their competitive careers, and in 7 of these 15, the pain persisted. ${ }^{23}$ Although causality is difficult to assess, in a cohort of 31 Olympic athletes complaining of back pain, a greater prevalence of degenerative spine changes than expected in the general population has also been reported. ${ }^{31}$ However, a number of studies downplay the long-term implications of degenerative changes in athletes' spines. Despite a higher incidence of degenerative spinal changes compared with non-athlete or population-based cohorts, some studies do not demonstrate an increased incidence of back pain or other spine symptomatology. ${ }^{18,32,37}$

Further longitudinal study is needed to determine the impact of collision sports on quality of life and health care expenses, as current evidence for causation is circumstantial. A prospectively collected cohort of motocross riders followed to determine the long-term sequelae of repetitive injury would be important. As technology improves, accelerometers and other devices could help quantify the relationship between repetitive injury, time, and degenerative changes, and perhaps create a long-term risk-based formula for exposure to potential injury or premature aging.

It is also unclear whether accelerated spinal column degeneration predisposes the adolescent population to catastrophic spinal cord injury. Cervical stenosis is implicated as a risk factor for spinal cord injury. As narrowed spinal canal diameter has been correlated with the risk of complete spinal cord injury, 4,9,20,28 it leads one to wonder if the degenerative changes increase the risk of serious injury to the spinal cord. However, this is difficult to tease out from the nature of the sport and high-velocity impact. In our motocross cohort, $6(75 \%)$ of 8 of patients presenting with acute fractures had evidence of degenerative changes in their spines, and 1 patient presented with a complete spinal cord injury; it is tempting to speculate that racing motocross simply increases the risk of spinal fractures and spinal cord injury.
Recently, professional motorsports have recognized the need for and mandated the use of additional safety equipment. Similar to the HANS (head and neck support) device used in professional car racing (http://hansdevice. com/Home.html), cervical protection devices such as the those manufactured by Leatt (http://www.leatt.com) have become accepted at the highest levels of professional motocross racing. These semi-rigid horse-collar-like devices are designed to transmit and dissipate forces in the event of impact. While non-industry evaluation is lacking, this attention to cervical spine injury in motocross is heartening. Turtle-shell back protectors are also commonly employed along with a full complement of body armor and helmet. Since professional riders have adopted these devices as standard protective equipment, we hope there will be a trickle-down effect in which younger athletes clamor for this technology. At this point, there are juvenile-size collars available, but these are not sized for the youngest of riders. Also notable is the Leatt company's emphasis on proper fitting, akin to recommendations for appropriate professional helmet sizing. In our survey of 139 active riders under the age of $18,81 \%$ reported wearing a rigid neck brace (study recently submitted for publication). ${ }^{26} \mathrm{We}$ strongly feel that athletes and parents should demand that cervical protection be standard for all recreational, training, and competitive riding.

Not included in the present study are data involving transient neuropraxias and return to play. These so-called "stingers" or "burners" to the cervical cord or nerve roots due to a concussive or compressive injury in the absence of cervical fracture. Again, as these injuries normally occur due to hyperflexion or hyperextension, spinal canal narrowing has been implicated as a risk factor ${ }^{33,36,42}$ and the extent of increased risk due to sport-related accelerated spinal degeneration remains unknown. Regardless of cause, when a neuropraxic injury or brachial plexus/root "stinger" occurs, timing of return to contact sports must be addressed in the same way return to play following concussion has been addressed. Education of athletes, parents, and supervising adults, including coaches and medical professionals, should be considered. It has been recommended that medical evaluation include assessment of cervical stenosis, with asymptomatic functional stenosis being an absolute contraindication for return to high-risk sports ${ }^{4-6,8,15,43}$ such as motocross. Beyond this, the decision to return to sport following neuropraxia and the timing of the return should be considered on a case-by-case basis, recognizing that there is scant information to guide physicians and their patients.

There are several shortcomings of this study. The major limitation is the small size of both cohorts and the selection bias both in motocross riders undergoing spinal imaging and control patients also undergoing spinal imaging. We felt that having a diverse control cohort most accurately reflected the general pediatric population, but including football players and gymnasts who are involved in impact activities may have resulted in an increase in degenerative spinal findings in our controls too, and this could have lessened the degree of difference between these two populations. Additionally, there are limitations 
in imaging modalities, as CT is more sensitive in detecting bony abnormalities and MRI more sensitive in detecting soft tissue abnormalities. In our study, $10.8 \%$ of patients had MRI or plain radiographs (most had CT); thus we do not feel this had a large impact, but standardized imaging selection balancing cost, radiation exposure, and sensitivity should be considered in future prospective studies.

\section{Conclusions}

We found an increase in the number of degenerative findings in the cervical and thoracic spines but not in the lumbar spine of motocross riders compared with agematched controls. Although the long-term consequences of these findings are unknown, riders and parents should be aware of these potential findings and decide whether continued participation is worth the risk and benefits. Increased safety through educating parents and athletes of potential risks, encouraging prompt medical attention in the event of injury, and the use of protective equipment such as cervical collars are encouraged.

\section{References}

1. Albright JP, Moses JM, Feldick HG, Dolan KD, Burmeister LF: Nonfatal cervical spine injuries in interscholastic football. JAMA 236:1243-1245, 1976

2. American Academy of Pediatrics Committee on Accident and Poison Prevention: All-terrain vehicles: two-, three-, and four-wheeled unlicensed motorized vehicles. Pediatrics 79:306-308, 1987

3. Brigham CD, Adamson TE: Permanent partial cervical spinal cord injury in a professional football player who had only congenital stenosis. A case report. J Bone Joint Surg Am 85-A:1553-1556, 2003

4. Cantu RC: Stingers, transient quadriplegia, and cervical spinal stenosis: return to play criteria. Med Sci Sports Exerc 29 (7 Suppl):S233-S235, 1997

5. Cooper MT, McGee KM, Anderson DG: Epidemiology of athletic head and neck injuries. Clin Sports Med 22:427443, vii, 2003

6. Dailey A, Harrop JS, France JC: High-energy contact sports and cervical spine neuropraxia injuries: what are the criteria for return to participation? Spine (Phila Pa 1976) 35 (21 Suppl):S193-S201, 2010

7. Daniels DJ, Clark MJ, Puffer R, Luo TD, McIntosh AL, Wetjen NM: High occurrence of head and spine injuries in the pediatric population following motocross accidents. J Neurosurg Pediatr [epub ahead of print January 2, 2015. DOI: 10.3171/2014.9.PEDS14149]

8. Davis G, Ugokwe K, Roger EP, Benzel EC, Cantu RC, Rogers M, et al: Clinics in neurology and neurosurgery of sport: asymptomatic cervical canal stenosis and transient quadriparesis. Br J Sports Med 43:1154-1158, 2009

9. Eismont FJ, Clifford S, Goldberg M, Green B: Cervical sagittal spinal canal size in spine injury. Spine (Phila Pa 1976) 9:663-666, 1984

10. Gatt CJ Jr, Hosea TM, Palumbo RC, Zawadsky JP: Impact loading of the lumbar spine during football blocking. Am J Sports Med 25:317-321, 1997

11. Gerbino PG, d'Hemecourt PA: Does football cause an increase in degenerative disease of the lumbar spine? Curr Sports Med Rep 1:47-51, 2002

12. Gobbi A, Tuy B, Panuncialman I: The incidence of motocross injuries: a 12-year investigation. Knee Surg Sports Traumatol Arthrosc 12:574-580, 2004

13. Golightly YM, Marshall SW, Callahan LF, Guskiewicz K:
Early-onset arthritis in retired National Football League players. J Phys Act Health 6:638-643, 2009

14. Gorski TF, Gorski YC, McLeod G, Suh D, Cordero R, Essien F, et al: Patterns of injury and outcomes associated with motocross accidents. Am Surg 69:895-898, 2003

15. Gottschalk AW, Andrish JT: Epidemiology of sports injury in pediatric athletes. Sports Med Arthrosc 19:2-6, 2011

16. Grange JT, Bodnar JA, Corbett SW: Motocross medicine. Curr Sports Med Rep 8:125-130, 2009

17. Healy JF, Healy BB, Wong WH, Olson EM: Cervical and lumbar MRI in asymptomatic older male lifelong athletes: frequency of degenerative findings. J Comput Assist Tomogr 20:107-112, 1996

18. Hogan BA, Hogan NA, Vos PM, Eustace SJ, Kenny PJ: The cervical spine of professional front-row rugby players: correlation between degenerative changes and symptoms. Ir J Med Sci 179:259-263, 2010

19. Hördegen KM: [The spine and horseback riding.] Schweiz Med Wochenschr 105:668-675, 1975 (Ger)

20. Kang JD, Figgie MP, Bohlman HH: Sagittal measurements of the cervical spine in subaxial fractures and dislocations. An analysis of two hundred and eighty-eight patients with and without neurological deficits. J Bone Joint Surg Am 76:1617-1628, 1994

21. Kartal A, Yildiran I, Senköylü A, Korkusuz F: Soccer causes degenerative changes in the cervical spine. Eur Spine J 13:76-82, 2004

22. Kennedy RD, Potter DD, Osborn JB, Zietlow S, Zarroug AE, Moir CR, et al: Childhood motocross truncal injuries: highvelocity, focal force to the chest and abdomen. BMJ Open 2:e001848, 2012

23. Konermann W, Sell S: [The spine-a problem area in high performance artistic gymnastics. A retrospective analysis of 24 former artistic gymnasts of the German A team.] Sportverletz Sportschaden 6:156-160, 1992 (Ger)

24. Lark SD, McCarthy PW: Cervical range of motion and proprioception in rugby players versus non-rugby players. $\mathbf{J}$ Sports Sci 25:887-894, 2007

25. Larson AN, Stans AA, Shaughnessy WJ, Dekutoski MB, Quinn MJ, McIntosh AL: Motocross morbidity: economic cost and injury distribution in children. J Pediatr Orthop 29:847-850, 2009

26. Luo TD, Clarke MJ, Zimmerman AK, Quinn M, Daniels DJ, McIntosh AL: Concussion symptoms in youth motocross riders: a prospective, observational study. J Neurosurg Pediatr [epub ahead of print January 2, 2015. DOI: 10.3171/2014.11. PEDS14127]

27. Maffulli N: Intensive training in young athletes. The orthopaedic surgeon's viewpoint. Sports Med 9:229-243, 1990

28. Matsuura P, Waters RL, Adkins RH, Rothman S, Gurbani N, Sie I: Comparison of computerized tomography parameters of the cervical spine in normal control subjects and spinal cord-injured patients. J Bone Joint Surg Am 71:183-188, 1989

29. Micheli LJ: Overuse injuries in children's sports: the growth factor. Orthop Clin North Am 14:337-360, 1983

30. O'Brien CP: "Rugby neck": cervical degeneration in two front row rugby union players. Clin J Sport Med 6:56-59, 1996

31. Ong A, Anderson J, Roche J: A pilot study of the prevalence of lumbar disc degeneration in elite athletes with lower back pain at the Sydney 2000 Olympic Games. Br J Sports Med 37:263-266, 2003

32. Oztürk A, Ozkan Y, Ozdemir RM, Yalçin N, Akgöz S, Saraç $\mathrm{V}$, et al: Radiographic changes in the lumbar spine in former professional football players: a comparative and matched controlled study. Eur Spine J 17:136-141, 2008

33. Penning L: Some aspects of plain radiography of the cervical spine in chronic myelopathy. Neurology 12:513-519, 1962

34. Quarrie KL, Cantu RC, Chalmers DJ: Rugby union injuries 
to the cervical spine and spinal cord. Sports Med 32:633653, 2002

35. Scher AT: Premature onset of degenerative disease of the cervical spine in rugby players. S Afr Med J 77:557-558, 1990

36. Scher AT: Spinal cord concussion in rugby players. Am J Sports Med 19:485-488, 1991

37. Schmitt H, Brocai DR, Carstens C: Long-term review of the lumbar spine in javelin throwers. J Bone Joint Surg Br 83:324-327, 2001

38. Schneider RC, Papo M, Soto Alvarez C: The effects of chronic recurrent spinal trauma in high-diving. A study of Acapulco's divers. J Bone Joint Surg Am 44-A:648-656, 1962

39. Semon RL, Spengler D: Significance of lumbar spondylolysis in college football players. Spine (Phila Pa 1976) 6:172-174, 1981

40. Tall RL, DeVault W: Spinal injury in sport: epidemiologic considerations. Clin Sports Med 12:441-448, 1993

41. Thomas BE, McCullen GM, Yuan HA: Cervical spine injuries in football players. J Am Acad Orthop Surg 7:338-347, 1999

42. Torg JS, Guille JT, Jaffe S: Injuries to the cervical spine in American football players. J Bone Joint Surg Am 84A:112-122, 2002

43. Triantafillou KM, Lauerman W, Kalantar SB: Degenerative disease of the cervical spine and its relationship to athletes. Clin Sports Med 31:509-520, 2012

44. Tsirikos A, Papagelopoulos PJ, Giannakopoulos PN, Boscainos PJ, Zoubos AB, Kasseta M, et al: Degenerative spondyloarthropathy of the cervical and lumbar spine in jockeys. Orthopedics 24:561-564, 2001
45. Watson AW: Sports injuries in footballers related to defects of posture and body mechanics. J Sports Med Phys Fitness 35:289-294, 1995

46. Weir DR, Jackson JS, Sonnega A: National Football League Player Care Foundation: Study of Retired NFL players. NFL Player Engagement. (https://www.nflplayerengagement. com/media/111949/univmich2009_retired_players_study. pdf) [Accessed November 2, 2014]

\section{Author Contributions}

Conception and design: Daniels, McIntosh, Larson. Acquisition of data: Daniels, Puffer. Analysis and interpretation of data: Daniels, Puffer. Drafting the article: Clarke, Daniels, Luo. Critically revising the article: all authors. Reviewed submitted version of manuscript: Clarke, Daniels, Luo, McIntosh, Larson, Wetjen. Approved the final version of the manuscript on behalf of all authors: Clarke. Statistical analysis: Daniels. Administrative/technical/material support: Clarke, McIntosh, Wetjen. Study supervision: Clarke, McIntosh, Wetjen.

\section{Correspondence}

Michelle J. Clarke, Department of Neurologic Surgery, Mayo Clinic, 200 First St. SW, Rochester MN 55906. email: clarke. michelle@mayo.edu. 